\title{
Weakening of lower tropospheric temperature gradient between Indian landmass and neighbouring oceans and its impact on Indian monsoon
}

\author{
S M BAWISKAR \\ Indian Institute of Tropical Meteorology, Dr. Homi Bhabha Road, Pune 411 008, India. \\ e-mail:bawiskar@hotmail.com bawiskar@tropmet.res.in
}

The study shows that in the scenario of global warming temperature gradient (TG) between Indian landmass and Arabian Sea/Bay of Bengal is significantly decreasing in the lower troposphere with maxima around $850 \mathrm{hPa}$. TG during pre-monsoon (March to May) is reducing at a significant rate of $0.036^{\circ}$ year (Arabian Sea) and $0.030^{\circ}$ year (Bay of Bengal). The above alarming results are based on sixty years (1948-2007) of daily temperature and wind data extracted from CDAS-NCEP/NCAR reanalysis datasets. TG based on ERA-40 data also indicates a decreasing trend of $0.0229^{\circ}$ year and $0.0397^{\circ}$ year for Arabian Sea and Bay of Bengal respectively. As TG is not governed by any type of significant oscillation, there is a possibility of TG tending to zero. It is further observed that the rate of warming over the oceans is more than that over the land which has resulted into the weakening of TG. Pre-monsoon TG has significant correlations with

- All India Seasonal Monsoon Rainfall (AISMR),

- kinetic energy of waves 1 and 2 at $850 \mathrm{hPa}$,

- kinetic energy, and

- stream function at $850 \mathrm{hPa}$ over Indian landmass during monsoon season.

Except AISMR, the decreasing trends observed in all the above parameters are significant. All India rainfall for July and August together shows a significant decreasing trend of $0.995 \mathrm{~mm} /$ year. Reducing number of depressions and cyclonic storms and increasing number of break days during monsoon over India are the reflections of the weakening of TG.

\section{Introduction}

Sea surface temperature (SST) over the oceans neighbouring India has significant positive relation with All India Seasonal Monsoon Rainfall (AISMR). But they have opposite trends. The former has significant increasing trend while the latter shows a decreasing trend. Some of the studies in support of the above observations are given below.

There are number of studies reporting relationship between SSTs over the oceans neighbouring
India with Indian monsoon. Shukla (1975) suggested that colder SST anomalies over western Arabian Sea and Somali Coast may cause reduction in monsoon rainfall over India and neighbourhood. Rao and Goswami (1988) showed that March-April SSTs of homogeneous regions in southeastern Arabian Sea are significantly positively correlated with seasonal rainfall over India. Clark et al (2000) found that Indian Ocean SSTs are positively correlated with Indian rainfall index throughout the autumn, winter and early spring preceding the Indian summer monsoon rainfall.

Keywords. Weakening; temperature gradient; pre-monsoon; monsoon. 


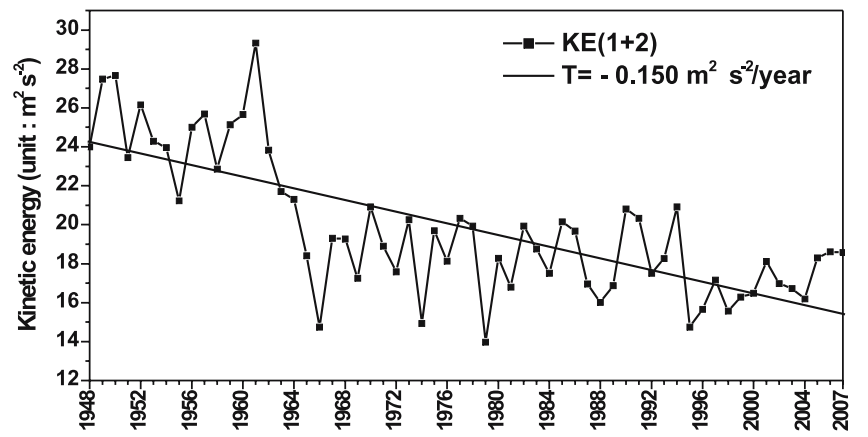

Figure 1. Inter-annual variation of kinetic energy of waves 1 and 2 around $10^{\circ} \mathrm{N}$ at $850 \mathrm{hPa}$ during monsoon season.

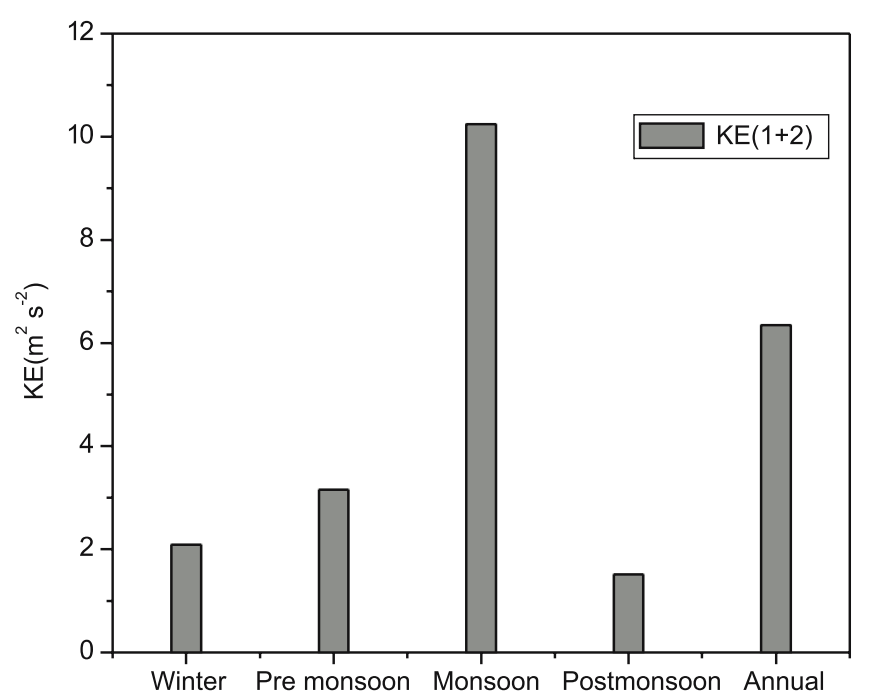

Figure 2. Climatology of kinetic energy of waves 1 and 2 around $10^{\circ} \mathrm{N}$ at $850 \mathrm{hPa}$ during different seasons.

Dash et al (2002) reported significant positive correlation with antecedent winter latent heat flux and SST anomalies over Arabian Sea. Kothawale et al (2008) showed that winter SST over Arabian Sea are positively and significantly correlated with seasonal monsoon rainfall over India.

Singh (2000) reported a rising trend in SST over north Indian Ocean. Rajeevan et al (2000) observed increasing trend in SST and cloudiness over equatorial Indian Ocean. Kothawale et al (2008) showed that annual SSTs of Arabian Sea, Bay of Bengal and equatorial south Indian Ocean have a significant warming trend of $0.7^{\circ} \mathrm{C}, 0.6^{\circ} \mathrm{C}$ and $0.5^{\circ} \mathrm{C}$ per 100 years with accelerated warming for recent three decades (1971-2002). Jadhav and Munot (2008) reported warming of the Bay of Bengal.

The decadal AISMR of five decades (1951-2000) based on daily gridded rainfall (Rajeevan et al 2006) are 953, 937, 933, 931 and $925 \mathrm{~mm}$. Kothawale et al (2008) claim that the rate of decrease of AISMR is higher during last three decades (1971-2002) as compared to the period from 1901 to 2002. All India rainfall for July and August together shows a significant decreasing trend of $0.995 \mathrm{~mm} /$ years (reported in the present study).

Number of break days and number of cyclones during monsoon seasons have significant influence on AISMR. A recent study (Ramesh Kumar et al 2009) has pointed out the role of SST warming trend in the tropical eastern Indian Ocean in inducing anomalous changes favourable for increased propensity of monsoon-breaks over the Indian subcontinent. Joseph and Simon (2005) reported 30\% increase in the number of break days in monsoon season during 1951-2000. Number of depressions/cyclonic storms during monsoon season is decreasing (Jadhav and Munot 2008).

The above findings indicate that SSTs over oceans neighbouring India have significant positive relationship with AISMR but they have opposite trends. The present study brings out the root cause of the decreasing trends observed in many parameters during monsoon season.

\section{Data}

Global temperate and wind ( $\mathrm{u} \& \mathrm{v}$ ) data for 60 years (1948-2007) are extracted from real time CDAS-NCEP/NCAR reanalysis data. Rainfall data for the corresponding sixty years is taken from homogenous Indian monthly rainfall datasets available at www.tropmet.res.in and daily gridded rainfall data published by Rajeevan et al (2006).

\section{Results and discussion}

\subsection{Motivation}

Bawiskar et al (2009) reported a significant positive correlation (99\% level) between daily all India rainfall during monsoon season (June to September) and daily kinetic energy of waves 1 and $2[\mathrm{KE}(1+2)]$ around $10^{\circ} \mathrm{N}$ at $850 \mathrm{hPa}$ and further claim that $\mathrm{KE}(1+2)$ holds a key to intraseasonal variations of AISMR. Inter-annual variation of same $\mathrm{KE}(1+2)$ on seasonal (June to September) scale shows a decreasing trend of $0.150 \mathrm{~m}^{2} \mathrm{~s}^{-2} /$ year (figure 1) which is significant at 99\%. Level of significance is tested by Mann-Kendall rank test. Kulkarni and Storch (1995) showed that the presence of moderate serial correlation within a series makes Mann-Kendall rank test liberal so that it signals erroneously the presence of significant trends. They suggested to filter out the autocorrelation of lag 1 (persistency) from the series before testing the trend. Trend in figure 1 is significant even after removing the persistency. 
Table 1. Trend analysis of temperature gradient between Indian landmass and Arabian Sea.

\begin{tabular}{cccccc}
\hline $\begin{array}{l}\text { Level } \\
\text { (hpa })\end{array}$ & $\begin{array}{c}\text { Winter } \\
(\mathrm{JF})\end{array}$ & $\begin{array}{c}\text { Pre-monsoon } \\
(\mathrm{MAM})\end{array}$ & $\begin{array}{c}\text { Monsoon } \\
(\mathrm{JJAS})\end{array}$ & $\begin{array}{c}\text { Post-monsoon } \\
(\text { OND })\end{array}$ & Annual \\
\hline 100 & 0.003 & -0.006 & $-0.021^{* *}$ & -0.002 & $-0.009^{*}$ \\
150 & $0.011^{* *}$ & $0.011^{* *}$ & $-0.018^{* *}$ & 0.004 & -0.001 \\
200 & $0.020^{* *}$ & $0.016^{* *}$ & $-0.009^{* *}$ & $0.008^{* *}$ & $0.006^{* *}$ \\
300 & $0.013^{* *}$ & $0.011^{* *}$ & $0.009^{*}$ & $0.005^{*}$ & $0.009^{* *}$ \\
400 & 0.009 & $0.009^{* *}$ & 0.004 & 0.003 & $0.006^{* *}$ \\
500 & $0.007^{*}$ & 0.003 & $-0.005^{*}$ & 0.004 & 0.001 \\
600 & 0.004 & -0.004 & 0.004 & 0.004 & 0.002 \\
700 & $-0.016^{* *}$ & $-0.021^{* *}$ & $-0.007^{* *}$ & 0.003 & $-0.009^{* *}$ \\
$\mathbf{8 5 0}$ & $-\mathbf{0 . 0 3 2 ^ { * * }}$ & $-\mathbf{0 . 0 3 6 ^ { * * }}$ & $-\mathbf{0 . 0 2 1}$ & $-\mathbf{0 . 0 2 9}$ & $-0.028^{* *}$ \\
1000 & $-0.019^{* *}$ & $-0.021^{* *}$ & $-0.012^{* *}$ & $-0.024^{* *}$ & $-0.018^{* *}$ \\
\hline
\end{tabular}

(*) Significant at $95 \% ;(* *)$ Significant at $99 \%$.

Figure 2 gives the climatology of $\mathrm{KE}(1+2)$ around $10^{\circ} \mathrm{N}$ at 850 during winter (JF), premonsoon (MAM), monsoon (JJAS), post-monsoon (OND) and annual. The letters in the brackets are the months considered for a particular season. An increase in the kinetic energy of global waves 1 and 2 from winter to summer indicates a positive relationship between $\mathrm{KE}(1+2)$ and global temperature around $10^{\circ} \mathrm{N}$. Now, the question is, in the scenario of global warming why is $\operatorname{KE}(1+2)$ decreasing?

Krishanmurty and Kanamitsu (1981) have pointed out that zonal asymmetry between (i) landmasses over Asia and Africa, and (ii) oceans (Atlantic and Pacific) provides a setting for an eventual differential heating that establishes zonal wave numbers 1 and 2. Temperature gradient (TG) between landmass and ocean is the quantitative measure of differential heating. Therefore, the study of TG is taken up to investigate the cause of decreasing trend of $\mathrm{KE}(1+2)$.

\subsection{Temperature gradient (TG)}

Areas considered to calculate TGs are:

- Arabian Sea $\left(20^{\circ} \mathrm{N}-10^{\circ} \mathrm{N}\right.$ and $\left.60^{\circ} \mathrm{E}-70^{\circ} \mathrm{E}\right)$,

- Indian landmass $\left(27.5^{\circ} \mathrm{N}-17.5^{\circ} \mathrm{N}\right.$ and $72.5^{\circ} \mathrm{N}-$ $\left.82.5^{\circ} \mathrm{N}\right)$, and

- Bay of Bengal $\left(20^{\circ} \mathrm{N}-10^{\circ} \mathrm{N}\right.$ and $\left.85^{\circ} \mathrm{E}-95^{\circ} \mathrm{E}\right)$.

All the three areas are of equal size. The major components of Indian monsoon are covered by these areas. Area over Arabian Sea covers the low level jet while the monsoon trough is covered by area over Indian landmass and the cyclogenesis area is covered by the area over Bay of Bengal. The series of the temperature difference between area average temperature over Indian landmass and Arabian Sea (TGIA), and Indian landmass and Bay of Bengal (TGIB) are constructed at 10 levels from 1000 to $100 \mathrm{hPa}$ for the years from
1948-2007 and subjected to linear trend analysis. Tables 1 and 2 present trend analysis for TGIA and TGIB respectively. Maximum decreasing trend is at $850 \mathrm{hPa}$ for pre-monsoon and monsoon months for both TGIA and TGIB and is significant at $99 \%$. Most of the trends are significant even after removing persistency. Hereafter, all further discussions are related to $850 \mathrm{hPa}$.

\subsection{Reason for the weakening of $T G$}

Figure $3(\mathrm{a}$ and $\mathrm{b})$ presents inter-annual variation of temperature (March to May) over Indian landmass and Arabian Sea respectively. Ocean temperature is rising significantly and surprisingly the temperature over land shows decreasing trend which is not significant. The difference between the temperature of Indian landmass and Arabian Sea, i.e., TGIA is presented in panel (c) of figure 3. This figure clearly indicates that the significant rise of temperature over the Arabian Sea has resulted into weakening of TGIA. Studies of Kothawale et al (2008) and Kothawale and Rupakumar (2005) also indicate that SST over Arabian Sea is rising $\left(0.7^{\circ} / 100\right.$ years $)$ at a faster rate than surface temperature $\left(0.5^{\circ} / 100\right.$ years $)$ over Indian landmass. The reducing trend in TGIA is highly significant and is decreasing at $0.036^{\circ}$ year. A similar analysis is presented for monsoon season in panels (d), (e) and (f). The results relating to Bay of Bengal (TGIB) are presented in figure 4 and are similar to the results of TGIA. ERA-40 data (1959-2001) also show significant decreasing trend of $0.0229^{\circ}$ year and $0.0397^{\circ}$ year for TGIA and TGIB respectively. The figures are not repeated here.

\subsection{Relation among TG, AISMR, kinetic energy (KE), stream function (SF) and $K E(1+2)$}

Table 3 gives correlation matrix for TGIA, TGIB, AISMR, KE, KE $(1+2)$ and $\mathrm{SF}$. $\mathrm{KE}$ and $\mathrm{SF}$ 
Table 2. Trend analysis of temperature gradient between Indian landmass and Bay of Bengal.

\begin{tabular}{cccccc}
\hline $\begin{array}{c}\text { Level } \\
\text { hpa })\end{array}$ & $\begin{array}{c}\text { Winter } \\
(\mathrm{JF})\end{array}$ & $\begin{array}{c}\text { Pre-monsoon } \\
(\mathrm{MAM})\end{array}$ & $\begin{array}{c}\text { Monsoon } \\
(\mathrm{JJAS})\end{array}$ & $\begin{array}{c}\text { Post-monsoon } \\
(\mathrm{OND})\end{array}$ & Annual \\
\hline 100 & $0.014^{* *}$ & $0.008^{*}$ & $-0.025^{* *}$ & $0.017^{* *}$ & 0.000 \\
150 & 0.009 & $0.013^{* *}$ & $-0.020^{* *}$ & 0.003 & -0.001 \\
200 & $0.026^{* *}$ & $0.023^{* *}$ & -0.003 & $0.010^{* *}$ & $0.011^{* *}$ \\
300 & $0.014^{* *}$ & 0.002 & $0.006^{*}$ & -0.004 & 0.004 \\
400 & 0.005 & 0.003 & 0.001 & -0.002 & 0.001 \\
500 & -0.003 & 0.002 & -0.001 & 0.001 & 0.000 \\
600 & 0.004 & -0.003 & $-0.006^{* *}$ & 0.003 & -0.002 \\
700 & -0.004 & $-0.017^{* *}$ & $-0.009^{* *}$ & 0.002 & $-0.008^{* *}$ \\
$\mathbf{8 5 0}$ & $-\mathbf{0 . 0 1 4}$ & $-\mathbf{0 . 0 3 0 ^ { * * }}$ & $-\mathbf{0 . 0 2 9} \mathbf{9}^{* *}$ & $-\mathbf{0 . 0 1 8 ^ { * * }}$ & $-\mathbf{0 . 0 2 4 ^ { * * }}$ \\
1000 & -0.006 & $-0.022^{* *}$ & $-0.024^{* *}$ & $-0.022^{* *}$ & $-0.020^{* *}$ \\
\hline
\end{tabular}

(*) Significant at $95 \% ;(* *)$ Significant at $99 \%$.
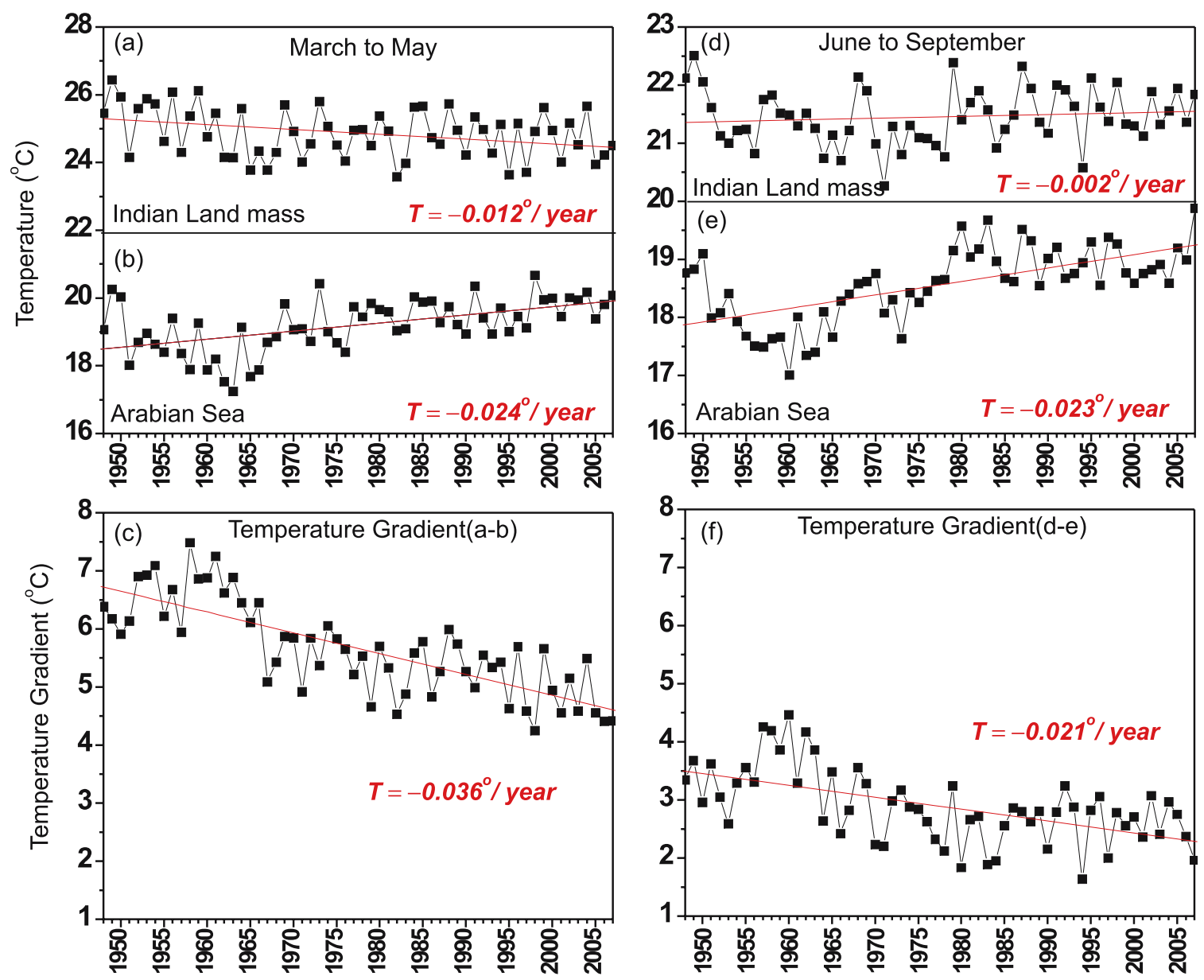

Figure 3. Inter-annual variations temperature at $850 \mathrm{hPa}$ over Indian landmass (a), Arabian Sea (b) and their temperature gradient (c) for pre-monsoon and (d, e and $\mathbf{f}$ ) for monsoon seasons.

represent the intensity and strength of monsoon circulation over central Indian landmass. Correlation coefficient (CC) outside the range -0.32 and 0.32 is significant at $99 \%$. Most of the relations, except relations between AISMR and TGIA/TGIB during monsoon months, are significant at $99 \%$.
Negative CCs for SF are due to the direction of monsoon circulation (cyclonic) over the Indian landmass. Monsoon TGIA/TGIB shows a weak relationship with AISMR. This is because, the monsoon rains not only disturb the meridional temperature pattern of pre-monsoon months but 

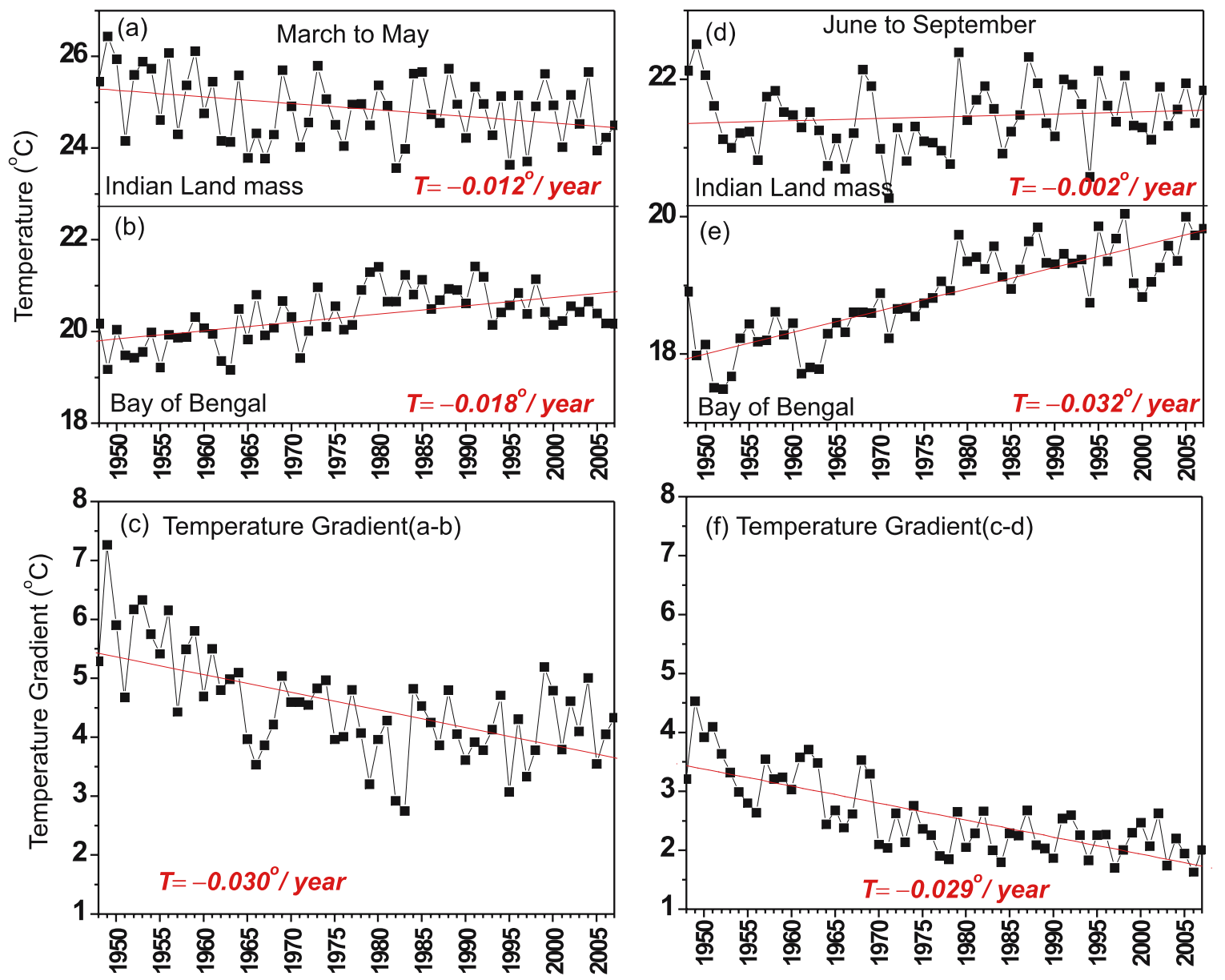

Figure 4. Inter-annual variations temperature at $850 \mathrm{hPa}$ over Indian landmass (a), Bay of Bengal (b) and their temperature gradient $(\mathbf{c})$ for pre-monsoon and $(\mathbf{d}, \mathbf{e}$ and $\mathbf{f})$ for monsoon seasons.

Table 3. Correlation matrix.

\begin{tabular}{|c|c|c|c|c|c|c|c|c|}
\hline & $\begin{array}{c}\text { TGIA } \\
\text { (MAM) }\end{array}$ & $\begin{array}{c}\text { TGIA } \\
\text { (JJAS) }\end{array}$ & $\begin{array}{c}\text { TGIB } \\
\text { (MAM) }\end{array}$ & $\begin{array}{c}\text { TGIB } \\
\text { (JJAS) }\end{array}$ & $\begin{array}{l}\text { AISMR } \\
\text { (JJAS) }\end{array}$ & $\begin{array}{c}\mathrm{KE} \\
\text { (JJAS) }\end{array}$ & $\begin{array}{c}\mathrm{KE}(1+2) \\
(\text { JJAS })\end{array}$ & $\begin{array}{c}\text { SF } \\
\text { (JJAS) }\end{array}$ \\
\hline TGIA(MAM) & 1 & 0.57 & 0.69 & 0.63 & 0.25 & 0.33 & 0.63 & -0.50 \\
\hline TGIA(JJAS) & & 1 & 0.39 & 0.75 & -0.17 & 0.08 & 0.46 & -0.38 \\
\hline TGIB(MAM) & & & 1 & 0.60 & 0.31 & 0.45 & 0.66 & -0.45 \\
\hline TGIB(JJAS) & & & & 1 & -0.11 & 0.28 & 0.67 & -0.46 \\
\hline $\operatorname{AISMR}(J J A S)$ & & & & & 1 & 0.30 & 0.41 & -0.29 \\
\hline $\mathrm{KE}(\mathrm{JJAS})$ & & & & & & 1 & 0.59 & -0.42 \\
\hline $\mathrm{KE}(1+2)(\mathrm{JJAS})$ & & & & & & & 1 & -0.67 \\
\hline $\mathrm{SF}(J J A S)$ & & & & & & & & 1 \\
\hline
\end{tabular}

TGIA: Temperature gradient between Indian landmass and Arabian Sea at $850 \mathrm{hPa}$; TGIB: Temperature gradient between Indian landmass and Bay of Bengal at $850 \mathrm{hPa}$; AISMR: All Indian seasonal monsoon rainfall; KE: Average kinetic energy over Indian landmass at $850 \mathrm{hPa}$; $\mathrm{KE}(1+2)$ : Kinetic energy of waves 1 and 2 around $10^{\circ} \mathrm{N}$ at $850 \mathrm{hPa}$; and $\mathrm{SF}$ : Stream function over Indian landmass at $850 \mathrm{hPa}$. Significant levels 0.25(95\%), 0.32(99\%) and 0.40(99.9).

also reduce the temperature of Indian landmass. Fall in temperature over Indian landmass leads to weak TG. The important aspect of the table is that pre-monsoon months TGIA/TGIB have significant positive correlation with AISMR. It means that strengthening of TG during March to May leads to a good monsoon season over India. Strengthening of TG is possible when warming of Indian landmass during March to May is significantly high as compared to the warming of surrounding oceans. 

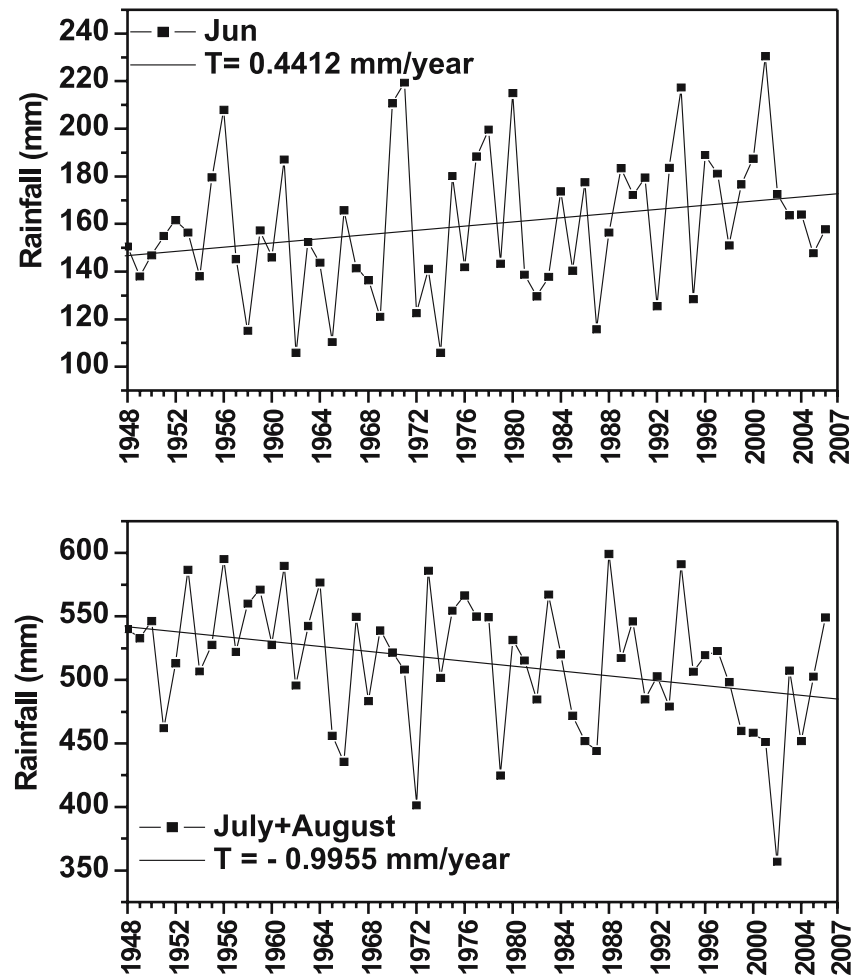

Figure 5. Inter-annual variations rainfall over Indian landmass during June (upper panel) and July and August together (lower panel).

\subsection{Trend analysis of AISMR, KE and SF}

Although, the decreasing trend of AISMR is not significant (Kothawale et al 2008), all India rainfall for July and August together shows significant decreasing trend (lower panel of figure 5) which is significant at $99 \%$. June rainfall has increasing trend (upper panel of figure 5), which must have diluted the overall decreasing trend of AISMR.

Figure 6 gives the inter-annual variation of kinetic energy and stream function $(\varphi)$ over the Indian landmass during June through August. Kinetic energy is reducing significantly with the time at the rate of $0.067 \mathrm{~m}^{2} \mathrm{~s}^{-2} /$ year. Negative value $\varphi$ indicates cyclonic circulation. The strength of cyclonic circulation is reducing at the rate of $0.16 \times 10^{6} \mathrm{~m}^{2} \mathrm{~s}^{-1} /$ year. As kinetic energy and stream function represent the intensity and strength of monsoon circulation, their weakening indicates that monsoon circulation over Indian landmass is weakening. Joseph and Simon (2005) have also reported the weakening monsoon current.

\subsection{Power spectrum analysis}

Parthasarathy et al (1994) analysed AISMR series from 1871 to 1993 and found a decadal variability with alternate epochs (lasting 3-4 decades) of above and below normal rainfall regimes. Does a
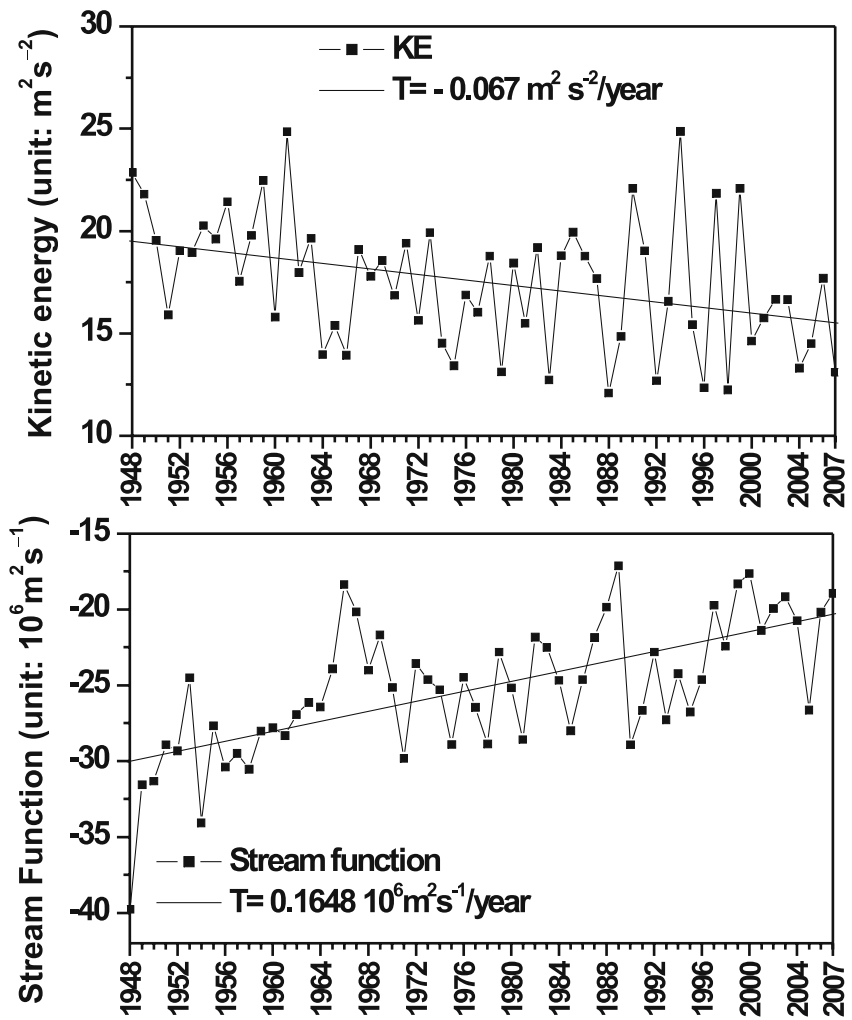

Figure 6. Inter-annual variation of kinetic energy (upper panel) and stream function (lower panel) at $850 \mathrm{hPa}$ over central Indian landmass during monsoon season.

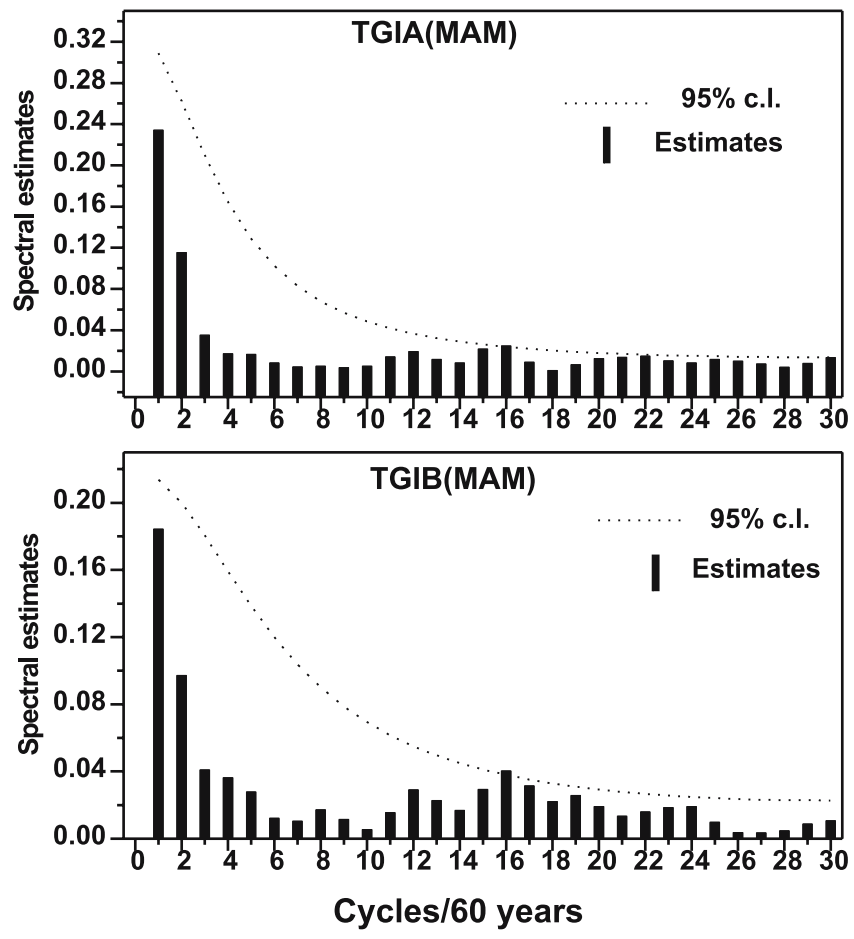

Figure 7. Power spectrum analysis of TGIA and TGIB.

similar cycle exist in TGIA or TGIB? Power spectrum analysis (Blackman and Tukey 1958) of premonsoon TGIA and TGIB is presented in figure 7. 
Bars are the estimates of a particular oscillation and dotted line represents $95 \%$ confidence level. Oscillation is said to be significant if the estimate crosses the confidence level. The estimates for both the series seem to cross the confidence line at cycle no. 16, indicating a periodicity similar to the ENSO type cycle of 3-5 years. Except for cycle 16, neither of the series is governed by any type of significant decadal oscillation.

Now, in absence of any significant decadal cycle, there is a possibility of TGIA/TGIB tending to zero. In such a scenario, the low level westerly jet (i.e., monsoon current over Arabian Sea) would become weak. This will lead to reduced rainfall activity over Indian Peninsula. The break like circulation will prevail for a longer period of time. The study of Ramesh Kumar et al (2009) indicates increasing trends in the duration and frequency of monsoon breaks and weakening of southwest summer monsoon flow in the recent decades into the Indian landmass. Joseph and Simons (2005) have also reported $30 \%$ increase of break days and weakening of southwest monsoon current.

\section{Conclusions}

The significant findings of the study are:

- Temperature gradient between Indian landmass and Arabian Sea (TGIA) and between Indian landmass and Bay of Bengal (TGIB) is significantly decreasing in the lower troposphere with maxima around $850 \mathrm{hPa}$. Pre-monsoon TGIA and TGIB are reducing at the rate of $0.036^{\circ} \mathrm{C} /$ year and $0.030^{\circ} \mathrm{C} /$ year respectively and are not governed by any type of significant oscillation.

- Temperature over Arabian Sea and Bay of Bengal is rising at a faster rate than the temperature over Indian landmass, which has resulted into significant weakening of TG between Indian landmass and the surrounding oceans.

- Pre-monsoon TGIA and TGIB have significant correlation with AISMR, KE, $\mathrm{KE}(1+2)$ and SF. Except AISMR, the decreasing trends observed in all the above-mentioned parameters are significant.

- Significant decreasing trend in kinetic energy and cyclonic circulation over Indian landmass during monsoon season is the indication of the weakening of monsoon circulation in the lower troposphere.

- June all India rainfall shows increasing trend whereas the rainfall during July and August together shows significant decreasing trend.

- Reducing number of depressions/cyclones and increasing number of break days are the reflections of weakening of TG.

\section{Acknowledgement}

Author is thankful to Prof. B N Goswami, Director, Indian Institute of Tropical Meteorology, for his keen interest and encouragement.

\section{References}

Bawiskar S M, Chipade M D and Puranik 2009 Energetics of lower tropospheric ultra long waves; A key to intraseasonal variability of Indian monsoon; J. Earth. Syst. Sci. 118(2) 1-6.

Blackman R B and Tukey J W 1958 The measurement of power spectra (New York: Dover Publication) p. 190.

Clark C O, Cole J E and Webster P J 2000 Indian Ocean SST and Indian summer rainfall: Predictive relationship and their decadal variability; J. Climate $\mathbf{1 3}$ 2503-2519.

Dash S K, Shekher M S and Singh O P 2002 Relationship between surface fields over: 1 . Indian Ocean and Monsoon rainfall over homogeneous zones of India; Mausam $\mathbf{5 3}$ 133-144.

Jadhav S K and Munot A A 2008 Warming SST of Bay of Bengal and decrease in formation of cyclonic disturbances over Indian region during southwest monsoon season; Theor. Appl. Clim. 96(3-4) 327-336, doi: 10.1007/s00704-008-00434-3.

Joseph P V and Anu Simon 2005 Weakening trend of southwest monsoon current through Peninsular India from 1950 to present; Curr. Sci. 89(4) 687-694.

Kothawale D R, Munot A A and Borgaonkar H P 2008 The temperature variability over the Indian Ocean and its relationship with Indian summer monsoon rainfall; Theor. Appl. Climatol. 92 31-45.

Kothawale D R and Rupakumar K 2005 On the recent changes in surface temperature trends over India; Geophys. Res. Lett. 132 L18714 doi: 10.1029/2005 GL23528.

Krishnamurti T N and Kanamitsu M 1981 Northern summer planetary scale monsoon during drought and normal rainfall months; In: Monsoon dynamics (eds) Sir James Lighthill and R P Pearce (Cambridge: Cambridge University Press) 19-48.

Kulkurni Ashwini and Hans von Storch 1995 Monte Carlo experiments on the effect of serial correlation on the Mann-Kendall test of trend; Meteorol Zeitscbrift N. F. 4 Jg. H.2 82-85.

Parthasarathy B, Munot A A and Kothawale D R 1994 AllIndia Monthly and Seasonal Rainfall Series: 1871-1993; Theor. Appl. Climatol. 49 217-224.

Rajeevan M, De U S and Prasad P K 2000 Decadal variation of sea surface temperature, cloudiness and monsoon depression in the north Indian Ocean; Curr. Sci. 79(3) $283-285$

Rajeevan M, Bhate Jyoti, Kale J D and Lal B 2006 High resolution daily gridded rainfall data for the Indian region: Analysis of break and active monsoon spells; Curr. Sci. 91(3) 295-306.

Ramesh Kumar M R, Krishnan R, Sankar S, Unnikrishnan A S and Pai D S 2009 Increasing trend of 'Break-Monsoon' conditions over India - Role of oceanatmosphere processes in the Indian Ocean; IEEE Geosci. Remote Sens. Lett. 6(2) 332-336.

Rao K G and Goswami B N 1988 Inter annual variation of sea surface temperature over Arabian Sea and 
Indian monsoon: A new perspective; Mon. Wea. Rev. 116 558-568.

Shulka J 1975 Effect of Arabian Sea Surface Temperature Anomaly on Indian Summer Monsoon: A numerical experiment with GFDL Model; J. Atmos. Sci. 32 503-511.

Singh O P 2000 Recent trends in summer temperature over north Indian Ocean; Indian J. Marine Sci. 29 7-11.

MS received 21 January 2009; revised 16 April 2009; accepted 19 April 2009 